\title{
PEMODELAN DANA BOS TERHADAP RATA-RATA NILAI RAPOT
}

\author{
Sugiarto ${ }^{1}$, Rezzy Eko Caraka ${ }^{2}$ \\ ${ }^{1}$ Kepala Sekolah SMAN 1 Moro, Tanjung Balai Karimun, Indonesia \\ ${ }^{2}$ Department of Statistics, Diponegoro University, Indonesia \\ e-mail: rezzyekocaraka@gmail.cm
}

\begin{abstract}
Abstrak-Penelitian ini bertujuan untuk menganalisis hubungan dana BOS terhadap nilai rata-rata rapot siswa. Aspek dana BOS yang diperhatikan antara lain adalah pengembangan perpustakaan, pembelajaran dan ekstrakurikuler siswa, langganan daya dan jasa, dan membantu siswa miskin. Nilai rapot siswa merupakan salah satu indicator dalam pencapaian belajar maupun prestasi belajar. Instrumen penelitian ini adalah catatan rapot siswa, observasi lapangan dan angket siswa berdasarkan analisis dapat disimpulkan bahwa sebesar 77,33\% rata-rata nilai rapot siswa (Y) dapat dijelaskan oleh variabel $\mathrm{X}_{1}, \mathrm{X}_{2}, \mathrm{X}_{3}, \mathrm{X}_{4}$, dan $\mathrm{X}_{5}$ sedangkan $22,67 \%$ lain dipengaruhi oleh faktor lain diluar penelitian ini. Pendidikan memiliki peranan pentingdalam menciptakan masyarakat yang cerdas, damai, terbuka, dan demokratis.
\end{abstract}

Keywords: BOS; Regresi Berganda; Prestasi; Pendidikan

\begin{abstract}
This study aimed to analyze the relationship of school operational assistance (BOS) funds to the value of the average rapport students. Aspects of BOS funds that are considered include the development of libraries, learning and extracurricular student, services, and helping poor students. Student's rapport is one indicator of the achievement of learning. The instrument of this study is rapport students and questionnaire of student's character, field notes, and observation sheets. Based analysis concludes that $77.33 \%$ the average value of rapport student $(Y)$ can be explained by variables $X_{1}, X 2, X 3, X 4$, and $X_{5}$, while $22.67 \%$ are influenced by other factors outside this research. Education has an important role in creating a society that is intelligent, peaceful, open, and democratic.
\end{abstract}

Keywords: BOS;Regression Multivaribale; Achievement;Education 


\section{PENDAHULUAN}

Pendidikan adalah suatu proses untuk meningkatkan pengetahuan guna menjadikan manusia berkualitas dan merupakan kebutuhan dasar untuk meningkatkan kecerdasan dan keterampilan. Pendidikan merupakan suatu upaya dalam meningkatkan sumber daya manusia dan merupakan tanggung jawab semua pihak, baik masyarakat, lembaga pendidikan maupun pemerintah. Untuk meningkatkan tingkat pendidikan, pemerintah Indonesia telah menyediakan fasilitas pendidikan hingga satuan administrasi terkecil. Pemerintah juga melaksanakan wajib belajar sembilan tahun guna mendorong masyarakat untuk berpartisipasi dalam sekolah.Pendidikan yang ditamatkan merupakan jenjang pendidikan tertinggi yang ditamatkan oleh seseorang, yang ditandai dengan sertifikat atau ijazah dari jenjang SD, SMP, SMA, dan PT. Pendidikan yang ditamatkan merupakan salah satu ukuran kualitas SDM, semakin tinggi tingkat pendidikan masyarakat, semakin tinggi tingkat kesejahteraannya.

Pendidikan merupakan aktivitas dan usaha manusia untuk meningkatkan kepribadiannya dengan jalan membina potensipotensi pribadinya, yaitu rohani (pikir, karsa, rasa, cipta dan budi pekerti). Pendidikan juga berarti lembaga yang bertanggung jawab menetapkan cita-cita (tujuan) pendidikan, isi, sistem, dan organisasi pendidikan. Lembagalembaga ini meliputi keluarga, sekolah dan masyarakat. Pendidikan adalah hal yang penting dalam kehidupan, bukan saja penting, bahkan pendidikan tidak bisa dipisahkan dari kehidupan.
Perkembangan dunia pendidikan yang maju tidak dipungkiri menjadi kebutuhan yang primer. Selain itu pendidikan merupakan suatu usaha atau proses yang ditujukan untuk membina kualitas sumber daya manusia seutuhnya agar dapat melakukan perannya dalam kehidupan secara fungsional, pendidikan juga merupakan indikator yang menunjukkan kualitas sumber daya manusia, dalam arti semakin baik pendidikan maka semakin baik pula kualitas sumber daya manusianya. Dengan terbentuknya sumber daya manusia yang berkualitas maka hal ini menunjukkan keberhasilan dalam pendidikan.

Prestasi belajar siswa dipengaruhi oleh faktor yang berasal dari dalam diri dan faktor yang berasal dari luar diri siswa. Faktor yang terdapat dalam diri siswa adalah intelegensi, motivasi, minat, bakat, kondisi fisik, sikap dan kebiasaan siswa, sedangkan yang termasuk faktor yang berasal dari luar diri siswa adalah keadaan sosial ekonomi, lingkungan, sarana dan prasarana, guru dan cara mengajarnya. Kemampuan ekonomi orang tua juga sangat berpengaruh tehadap prestasi belajar peserta didik. Orang tua dengan kemampuan ekonomi baik tentunya akan mampu menjamin kelancaran pembiayaan proses belajar dari putra-putrinya. Dampaknya tentunya pada kenyamanan siswa dalam belajar. Jadi dapat diasumsikan bila semakin rendah rasio siswa tidak mampu dalam suatu sekolah maka akan semakin rendah prestasi siswa di sekolah tersebut. Namun dengan hadirnya dana bantuan operasional sekolah sekarang ini diharapkan dapat mengubah asumsi tersebut. Bantuan Operasional Sekolah (BOS) 
diberikan kepada sekolah untuk dikelola sesuai dengan ketentuan yang ditetapkan pemerintah pusat. Besarnya dana untuk tiap sekolah ditetapkan berdasarkan jumlah murid. Lebih lanjut, tujuan utama di cetuskannya Program Bantuan Operasional Sekolah (BOS) adalah untuk meningkatkan prestasi belajar siswa. Dengan Bantuan Operasional Sekolah (BOS) maka siswa atau orang tua siswa tidak dipusingkan lagi dengan masalah-masalah pendanaan atau biaya sekolah. Sehingga pada akhirnya prestasi belajar siswa akan tercapai dengan lebih baik.

Di dalam buku petunjuk teknis penggunaan dana bantuan operasional sekolah (BOS) dan laporan keuangan bantuan operasional sekolah tahun anggaran 2012 yang diterbitkan oleh Direktorat Jenderal Pendidikan Dasar Kementerian Pendidikan dan Kebudayaan dijelaskan bahwa tujuan dari program BOS antara lain :1) Secara umum, program BOS bertujuan untuk meringankan beban masyarakat terhadap pembiayaan pendidikan dalam rangka wajib belajar 9 tahun yang bermutu. 2) Secara khusus, program BOS ini bertujuan agar murid ditingkat dasar dan menengah, yang berasal dari keluarga kurang/tidak mampu dapat membiayai keperluan sekolahnya, sehingga : a) Membebaskan pungutan bagi seluruh siswa SD/SDLB negeri dan SMP/SMPLB/SMPT (Terbuka) negeri terhadap biaya operasi sekolah, kecuali pada rintisan sekolah bertaraf internasional (RSBI) dan sekolah bertaraf internasional (SBI). Sumbangan/ pungutanbagi sekoah RSBI dan SBI harus tetap mempertimbangkan fungsipendidikan sebagai kegiatan nirlaba, sehinggapungutan/ sumbangan tidak boleh berlebihan. b) Membebaskan pungutan seluruh siswa miskin dari seluruhpungutan dalam bentuk apapun, baik di sekolah negeri maupunswasta. c) Meringankan beban biaya operasional sekolah bagi siswa di sekolah swasta

Adapun dana BOS selebihnya digunakan untuk membiayai kegiatan-kegitan berikut. Pertama, Pembiayaan seluruh kegiatan dalam rangka penerimaan siswa baru, yaitu biaya pendaftaran, penggandaan formulir, administrasi pendaftaran, dan pendaftaran ulang, pembuatan spanduk sekolah gratis, serta kegiatan lain yang berkaitan langsung dengan kegiatan tersebut (misalnya untuk fotocopy, konsumsi panitia, dan uang lembur dalam rangka penerimaan siswa baru, dan lainnya yang relevan). Kedua, Pembelian buku referensi dan pengayaan untuk dikoleksi di perpustakaan (hanya bagi sekolah yang tidak menerima DAK). Ketiga, Pembelian buku teks pelajaran lainnya (selain yang wajib dibeli) untuk dikoleksi di perpustakaan.

Keempat, Pembiayaan kegiatan pembelajaran remedial, pembelajaran pengayaan, pemantapan persiapan ujian, olahraga, kesenian, karya ilmiah remaja, pramuka, palang merah remaja, unit kesehatan sekolah, dan sejenisnya (misalnya untuk honor jam mengajar tambahan di luar jam pelajaran, biaya transportasi dan akomodasi siswa/guru dalam rangka mengikuti lomba, fotocopy, membeli alat olahraga, alat kesenian, perlengkapan kegiatan ekstrakulikuler, dan biaya pendaftaran mengikuti lomba).

Kelima, 
Pembiayaan ulangan harian, ulangan umum, ujian sekolah, dan laporan hasil belajar siswa (misalnya untuk fotocopy/penggandaan soal, honor koreksi ujian, dan honor guru dalam rangka penyusunan rapor siswa).

Keenam, Pembelian bahan-bahan habis pakai seperti buku tulis, kapur tulis, pensil, spidol, kertas, bahan praktikum, buku induk siswa, buku inventaris, langganan koran/majalah pendidikan, minuman dan makanan ringan untuk kebutuhan sehari-hari di sekolah, serta pengadaan suku cadang alat kantor. Ketujuh, Pembiayaan langganan daya dan jasa, yaitu listrik, air, telepon, internet, termasuk untuk pemasangan barujika sudah ada jaringan di sekitar sekolah. Khusus di sekolah yang tidak ada jaringan listrik, dan jika sekolah tersebut memerlukan listrik untuk proses belajar mengajar di sekolah, maka diperkenankan untuk membeli genset. Kedelapan, Pembiayaan perawatan sekolah, yaitu pengecetan, perbaikan atap bocor, perbaikan pintu dan jendela, perbaikan mebeler, perbaikan sanitasi sekolah, perbaikan lantai ubin/keramik, dan perawatan fasilitas sekolah lainnya.

Kesembilan, Pembayaran honorarium bulanan guru honorer dan tenaga kependidikan honorer. Untuk sekolah SD diperbolehkan untuk membayar honor tenaga yang membantu administrasi BOS. Kesepuluh, Pengembangan profesi guru seperti pelatihan, KKG/MGMP dan KKKS/MKKS. Khusus untuk sekolah yang memperoleh hibah/block grant pengembangan KKG/MGMP atau sejenisnya pada tahun anggaran yang sama tidak diperkenankan menggunakan dana BOS untuk peruntukan yang sama. Kesebelas, Pemberian bantuan biaya transportasi bagi siswa miskin yang menghadapi masalah biaya transport dari dan ke sekolah. Jika dinilai lebih ekonomis, dapat juga untuk membeli alat transportasi sederhana yang akan menjadi barang inventaris sekolah (misalnya sepeda, perahu penyebrangan, dll). Keduabelas, Pembiayaan pengelolaan BOS seperti alat tulis kantor (ATK), penggandaan, surat-menyurat, insentif bagi bendahara dalam rangka penyusunan laporan BOS dan biaya transportasi dalam rangka mengambil dana BOS di Bank/PT Pos.

Ketigabelas, Pembelian komputer dekstop untuk kegiatan belajar siswa, maksimum 1 set untuk SD dan 2 set untuk SMP, pembelian 1 unit printer, serta kelengkapan komputer seperti hard disk, flash disk, CD/DVD, dan suku cadang komputer/printer. Keempatbelas, Jika komponen 1 s.d 13 di atas telah terpenuhi pendanaannya dari BOS dan masih terdapat sisa dana, maka sisa dana BOS tersebut dapat digunakan untuk membeli alat peraga, media pembelajaran, mesin ketik, mebeler sekolah, dan peralatan untuk UKS. Bagi sekolah yang telah menerima DAK, tidak diperkenankan menggunakan dana BOS untuk peruntukan yang sama.

Penggunaan dana BOS untuk transportasi dan uang lelah bagi guru PNS diperbolehkan hanya dalam rangka penyelenggaraan suatu kegiatan sekolah selain kewajiban jam mengajar. Besaran atau satuan biaya untuk transportasi dan uang lelah guru PNS yang bertugas di luar jam mengajar tersebut harus mengikuti batas kewajaran. Pemerintah Daerah wajib 
mengeluarkan peraturan tentang batas kewajaran tersebut di daerah masing-masing dengan mempertimbangkan faktor sosial ekonomi, faktor geografis dan faktor lainnya.

Beberapa pendapat para ahli tentang definisi tentang belajar. Cronbach, Harold Spears dan Geoch dalam Sardiman A.M (2005:20). Cronbach memberikan definisi : "Learning is shown by a change in behavior as a result of experience". "Belajar adalah memperlihatkan perubahan dalam perilaku sebagai hasil dari pengalaman". Harold Spears memberikan batasan: "Learning is to observe, to read, to initiate, to try something themselves, to listen, to follow direction"Belajar adalah mengamati, membaca, berinisiasi, mencoba sesuatu sendiri, mendengarkan, mengikuti petunjuk/arahan dan Geoch, mengatakan "Learning is a change in performance as a result of practice”. Belajar adalah perubahan dalam penampilan sebagai hasil praktek. Belajar itu senantiasa merupakan perubahan tingkah laku atau penampilan, dengan serangkaian kegiatan misalnya dengan membaca, mengamati, mendengarkan, meniru dan lain sebagainya. Juga belajar itu akan lebih baik kalau si subyek belajar itu mengalami atau melakukannya, jadi tidak bersifat verbalistik. Belajar sebagai kegiatan individu sebenarnya merupakan rangsangan-rangsangan individu yang dikirim kepadanya oleh lingkungan. Dengan demikian terjadinya kegiatan belajar yang dilakukan oleh seorang individu dapat dijelaskan dengan rumus antara individu dan lingkungan. Prestasi belajar adalah suatu hasil yang dicapai oleh siswa berdasarkan kemampuan belajarnya yang di nyatakan dalam nilai. Dengan nilai yang diperoleh seorang guru dapat mengetahui tingkat keberhasilan siswa dalam menerima materi yang di sampaikan, dengan begitu guru bisa mengetahui tingkat prestasi siswa apakah ada perubahan dari sebelumnya atau tidak. Dimana prestasi siswa ini dapat diukur melalui nilai dari raport selama satu semester.

\section{Uji Validitas}

Validitas menunjukkan sejauh mana suatu alat pengukur itu mengukur apa yang ingin diukur. Jika peneliti menggunakan kuesioner dalam pengumpulan data penelitian, maka kuesioner yang disusunnya harus mengukur apa yang ingin diukurnya. Suatu kuesioner dikatakan valid jika pertanyaan pada kuesioner mampu mengungkapkan sesuatu yang akan diukur oleh kuesioner.

Uji validitas menggunakan teknik korelasi Product Moment dengan menggunakan rumus sebagai berikut (Sujarweni dan Endrayanto, 2012):

$$
\mathrm{r}_{\mathrm{xy}}=\frac{n \sum_{i=1}^{n} x y-\left(\sum_{i=1}^{n} x \sum_{i=1}^{n} y\right)}{\sqrt{\left[n \sum_{i=1}^{n} x^{2}-\left(\sum_{i=1}^{n} x\right)^{2}\right]\left[n \sum_{i=1}^{n} y^{2}-\left(\sum_{i=1}^{n} y\right)^{2}\right]}}
$$

Keterangan: $\mathrm{n}=$ Banyaknya sampel, $\mathrm{x}=$ Skor masing-masing variabel pengamatan, $\mathrm{y}=$ Skor total

Hasil $\mathrm{r}_{\mathrm{xy}}$ dibandingkan mengetahui signifikansi koefisien korelasi dengan t tabel di mana $\mathrm{df}=\mathrm{n}-2$, jika $\mathrm{t}$ tabel $<\mathrm{t}$ hitung maka instrumen pertanyaan dikatakan valid. Berikut uji hipotesis yang digunakan untuk mengetahui signifikansi dari koefisien korelasi (Walpole dan Myers, 2012): 
Hipotesis

$$
\begin{aligned}
& \mathrm{H}_{0}: \rho=0 \\
& \mathrm{H}_{1}: \rho \neq 0
\end{aligned}
$$

Statistik uji

$$
\mathrm{t}_{\text {hit }}=\frac{r_{x y} \sqrt{n-2}}{\sqrt{1-r_{x y^{2}}}}
$$

\section{Kriteria uji}

$\mathrm{H}_{0}$ ditolak jika $\mathrm{t}_{\text {hit }}>\mathrm{t}_{\alpha / 2, \mathrm{n}-2}$, dengan $\mathrm{n}$ adalah banyaknya sampel dalam penelitian. Jika nilai $t_{\text {hit }}$ lebih besar dari t tabel maka dapat disimpulkan bahwa butir pertanyaan signifikan dan dinyatakan valid.

\section{Uji Reliabilitas}

Sujarweni dan Endrayanto menyatakan bahwa reliabilitas merupakan ukuran suatu kestabilan dan konsistensi responden dalam menjawab hal yang berkaitan dengan konstrukkonstruk pertanyaan yang merupakan dimensi suatu variabel dan disusun dalam suatu bentuk kuesioner. Uji reliabilitas dapat dilakukan secara bersama-sama terhadap seluruh butir pertanyaan. Jika nilai Alpha > 0,6 maka butir pertanyaan reliabel. Berikut formula untuk uji reliabilitas:

$$
\mathrm{r}=\left[\frac{m}{m-1}\right]\left[1-\frac{\sum_{i=1}^{n} \sigma_{b}^{2}}{\sigma_{t}^{2}}\right]
$$

keterangan: $\mathrm{r}=$ Reliabilitas Instrumen, $\mathrm{m}=$ banyaknya variabel, $\sum_{i=1}^{n} \sigma_{b}^{2} \quad=$ Jumlah varians butir, $\sigma_{t}^{2}=$ Varians Total

\section{Analisis Regresi Berganda}

Istilah regresi pertama kali diperkenalkan oleh Francis Galton tahun 1886 dan diperkuat oleh Karl Pearson tahun 1903. Menurut definisi Montgomery (1992), analisis regresi merupakan teknik statistik untuk menyelidiki dan memodelkan hubungan antar variabel. Dalam mengkaji hubungan antara beberapa variabel menggunakan analisis regresi terlebih dahulu menentukan satu variabel yang disebut variabel tidak bebas (Y) dan satu atau lebih variabel bebas (X). Jika ingin mengkaji hubungan atau pengaruh dua atau lebih variabel bebas terhadap variabel tak bebas, maka model regresi yang digunakan adalah model regresi linier berganda (multiple linier regression model). Analisis regresi linier berganda merupakan perluasan dari regresi linier sederhana. Perluasan tersebut dapat dilakukan dengan penambahan variabel bebas.

Untuk memahami model regresi linier berganda digunakan model regresi yang dinyatakan dalam persamaaan sebagai berikut:

$Y_{i}=\beta_{0}+\beta_{1} X_{1 i}+\beta_{2} X_{2 i}+\ldots+\beta_{k} X_{k i}+\varepsilon_{i}$ (2.1)

Di mana

$Y_{i}=$ variabel tak bebas untuk pengamatan ke $i$, dimana $i=1,2, \ldots, \mathrm{n}$

$X_{k i}=$ variabel bebas ke- $k$ untuk pengamatan ke- $i$,

$\beta_{0}=$ intersep (titik potong garis regresi terhadap sumbu y) atau nilai $Y$ pada saat $X=$ 0

$\beta_{1}, \beta_{2}, \ldots, \beta_{k}=$ kemiringan (slope) garis regresi yang menunjukkan besarnya perubahan nilai $Y$ jika $X$ berubah 1 unit. $\varepsilon_{i}=$ variabel error ke- $i$, diasumsikan $\{\varepsilon \sim$ $\left.\operatorname{NID}\left(0, \sigma^{2}\right)\right\}$

\section{Asumsi Model Regresi Linier}

Delam melakukan pemodelan regresi ada beberapa asumsi yang harus dipenuhi antara lain sebagai berikut. 
Normalitas. Apabila asumsi ini dipenuhi berarti data yang diambil berasal dari populasi normal yang berarti bahwa $\varepsilon_{\mathrm{i}} \sim \operatorname{NID}\left(0, \sigma^{2}\right)$. Asumsi kenormalan data diuji dengan menggunakan uji Kolmogorov-Smirnov. Caranya dengan membandingkan taraf signifikansi dari variable dependen pada output yang diperoleh dengan taraf signifikansi yang digunakan. Jika taraf signifikansi dari variable dependen lebih besar dari taraf signifikansi yang digunakan maka data tersebut berdistribusi normal.

Linieritas dan Kesamaan Varian. Linieritas adalah tidak terdapatnya hubungan antara hargaharga prediksi dengan harga residual. Metode yang digunaka untuk memeriksa asumsi ini adalah dengan melihat plot residual terhadap harga-harga prediksi. Jika asumsi dipenuhi maka residual-residual akan didistribusikan secara random dan terkumpul di sekitar garis lurus yang melalui titik nol.

Autokorelasi. Uji ini digunakan untuk mendeteksi data yang ada apakah terjadi autokorelasi, artinya bahwa terjadi ketergantungan antara error yang ada, sedangkan pada asumsi kenormalan dinyatakan bahwa error $\left(\varepsilon_{i}\right)$ pada variable-variabel random tidak saling berkorelasi (independen). Salah satu cara mengetahui apakah error berkorelasi atau tidak adalah dengan pengujian statistic Durbin-Watson.

Non Multikolinieritas. Multikolinieritas adalah kejadian yang menginformasikan terjadinya hubungan antara variable-variabel bebas Xi dan yang terjadi hubungan yang cukup erat. Sehingga informasi yang dihasilkan dari variable-variabel yang saling berhubungan (kolinieritas) sangat sulit dan sulit dipisahkan pengaruhnya.

\section{Uji Hipotesis dalam Regresi Linier} Berganda. a) Uji Signifikansi Regresi (Uji kecocokan Model / uji F).

Hipotesis

$\mathrm{H}_{0}: \beta_{0}=\beta_{1}=0($ Model tidak cocok $)$

$\mathrm{H}_{1}$ : Minimal ada 1 i dengan $\beta_{\mathrm{i}} \neq 0$ ( Model cocok)

Taraf Signifikansi

$\alpha$ yang sering digunakan adalah $5 \%=0.05$

Statistik Uji

$\mathrm{F}=$ Daerah Penolakan

Manual : $\mathrm{H}_{0}$ ditolak jika $\mathrm{F}_{\text {hitung }}>\mathrm{F}_{\alpha, \mathrm{k}, \mathrm{n}-\mathrm{k}-\mathrm{l}}$

Tabel 1. Analisis Variansi Regresi Linier Berganda

\begin{tabular}{llllll}
\hline Sumber Variasi & \multicolumn{1}{c}{$\mathrm{Db}$} & $\mathrm{JK}$ & $\mathrm{KT}$ & $\mathrm{F}_{\text {hitung }}$ & $\mathrm{F}_{\text {tabel }}$ \\
\hline Regresi & $\mathrm{K}$ & $\mathrm{JKR}$ & $\mathrm{KTR}$ & $\mathrm{KTR} / \mathrm{KTS}$ & $\mathrm{F}_{\alpha, \mathrm{k}, \mathrm{n}-\mathrm{k}-1}$ \\
Sesatan & $\mathrm{n}-\mathrm{k}-1$ & JKS & KTS & & \\
Total & $\mathrm{n}-1$ & JKT & & & \\
\hline
\end{tabular}

b) Pengujian koefisien Regresi secara individual $\quad \alpha$ yang sering digunakan adalah $5 \%=0.05$

(Uji t)

Hipotesis

$\mathrm{H}_{0}: \beta_{\mathrm{i}}=0$ ( Variabel tidak berpengaruh )

$\mathrm{H}_{1}$ : Minimal ada 1 i dengan $\beta_{\mathrm{i}} \neq 0$ (Variabel

berpengaruh)

Taraf Signifikansi
Statistik Uji

$\mathrm{t}=\quad$ dengan $\mathrm{Se}(=$ Daerah Penolakan

$\mathrm{H}_{0}$ ditolak jika $\left|\mathrm{t}_{\text {hitung }}\right|>\mathrm{t}_{1-\alpha / 2, \mathrm{n}-\mathrm{k}-1}$ 


\section{Ukuran Kecocokan Model dalam Regresi}

\section{Linier Berganda}

Koefisien determinasi merupakan suatu nilai atau ukuran yang dapat digunakan untuk mengetahui seberapa jauh kecocokan dari suatu model regresi. Nilai $R^{2}$ menyatakan besar sumbangan variable bebas $X_{j}$ terhadap variable tak bebas $\mathrm{Y}$.

$\mathrm{R}^{2}=\mathrm{JKR} / \mathrm{JKT}=1-\mathrm{JKS} / \mathrm{JKT}$ dengan JKT $=\mathrm{JKR}+\mathrm{JKS}$
Sifat-sifat koefisien determinasi: 1) Merupakan besaran non negatif. 2) Batasnya adalah $0 \leq \mathrm{R}^{2}$ $\leq 1$

\section{METODOLOGI PENELITIAN}

Jenis data yang digunakan dalam penelitian ini adalah data primer yang diperoleh dari subjek penelitian dengan cara menyebarkan kuesioner terhadap siswa kelas XI dengan banyak responden sebanyak 60. Adapun instrument penelitian sebagai berikut :

Tabel 2 Instrumen Penelitian

\begin{tabular}{|c|c|c|c|}
\hline Variabel & Dimensi variabel & Indikator variabel & Pertanyaan \\
\hline \multirow{5}{*}{$\begin{array}{c}\text { Dana bantuan } \\
\text { operasional } \\
\text { sekolah } \\
\text { (petunjuk teknis } \\
\text { dana BOS (2014 } \\
: 16-19)\end{array}$} & Penggunaan dana BOS & $\begin{array}{l}\text { 1. Penggunaan dana BOS untuk pengembangan } \\
\text { perpustakaan }\end{array}$ & $1,2,3,4,5,6$ \\
\hline & $\begin{array}{c}\text { (penunjang keberhasilan } \\
\text { prestasi belajar) }\end{array}$ & $\begin{array}{l}\text { 2. Penggunaan dana BOS untuk pembelajaran } \\
\text { dan ekstrakurikuler siswa }\end{array}$ & $7,8,9,10,11$ \\
\hline & & $\begin{array}{l}\text { 3. Penggunaan dana BOS untuk langganan daya } \\
\text { dan jasa }\end{array}$ & $12,13,14$ \\
\hline & & $\begin{array}{l}\text { 4. Penggunaan dana BOS untuk membantu } \\
\text { siswa miskin }\end{array}$ & $15,16,17$ \\
\hline & & $\begin{array}{l}\text { 5. Pengunaan dana BOS untuk kegiatan dalam } \\
\text { rangka penerimaan siswa baru }\end{array}$ & $18,19,20$ \\
\hline
\end{tabular}

\section{HASIL DAN PEMBAHASAN}

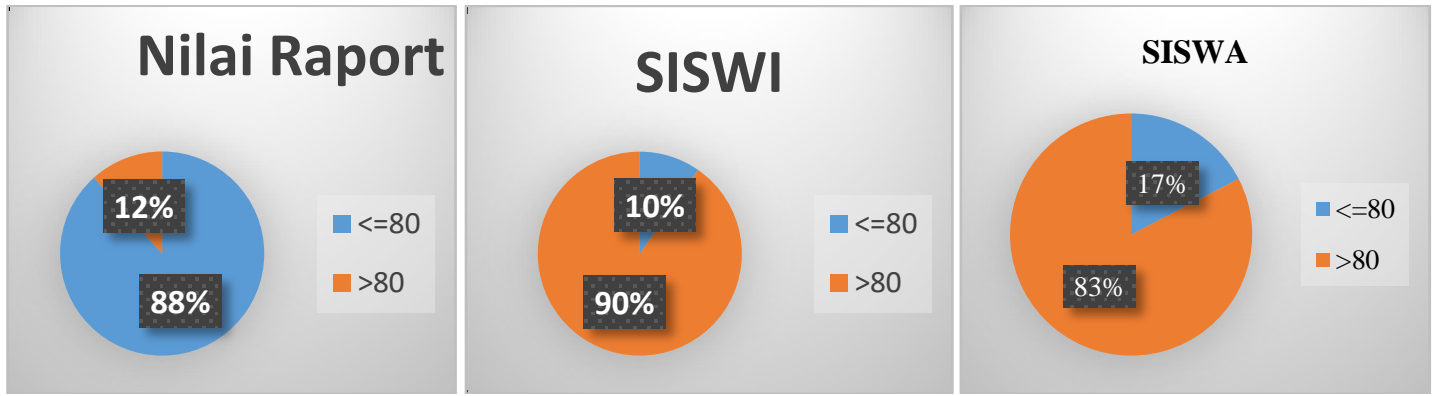

Gambar 1. Rata-rata nilai raport

Berdasarkan analisis dengan jumlah responden adalah 60 siswa dimana 32 orang laki-laki dan 28 orang perempuan. Dapat dilihat bahwa $88 \%$ siswa memiliki nilai raport $>=80$ dan $12 \%$ siswa memiliki nilai raport $<80$. Untuk jenis kelamin perempuan sebesar $90 \%$ memiliki nilai raport diatas 80 dan sebesar $10 \%$ perempuan memiliki nilai raport dibawah 80. Untuk Siswa sebesar $83 \%$ memiliki nilai rapor diatas 80 dan sebesar 17\% memiliki nilai rapor dibawah 80. Untuk lebih lengkap dapat dilihat pada tabel dibawah ini 
Tabel 3. Statistika Deskriptif

\begin{tabular}{lrrrrrrr}
\hline Variable & \multicolumn{1}{l}{ Jumlah } & \multicolumn{1}{l}{ Mean } & \multicolumn{1}{l}{ StDev } & Variance & Minimum & Median & Maximum \\
\hline Siswa & 32 & 81.531 & 3.436 & 11.805 & 76 & 81 & 93 \\
\hline Siswi & 28 & 81.857 & 2.965 & 8.794 & 75 & 82 & 88 \\
\hline
\end{tabular}

Berdasarkan tabel diatas dapat di lihat bahwa nilai ragam terbesar ada pada kategori siswa yakni sebesar 11.805 hal ini terindikasi bahwa terdapat siswa yang memiliki nilai yang kecil dan nilai yang besar sehingga pada kategori ini terdapat nilai keragaman yang besar. Nilai rata-rata raport tertinggi terdapat pada kategori Siswa yakni sebesar 93 dan nilai terendah terdapat pada kategori Siswi yakni sebesar 75 .

Pengujian validitas terhadap kuisioner dilakukan untuk menunjukkan sejauh mana kuisioner tersebut mengukur apa yang akan diukur. Pengujian dilakukan menggunakan analisis butir dengan mengkorelasikan skor masing-masing variabel dengan skor total pada masing-masing dimensi. Variabel-variabel pertanyaan diuji validitasnya. Hasil pengujian validitas untuk tiap-tiap variabel dalam masingmasing dimensi dapat dilihat pada Tabel 2 .
Tabel 3. Uji Validitas

\begin{tabular}{lccc}
\hline \multicolumn{1}{c}{ Variabel } & $\begin{array}{c}\text { Korelasi } \\
\text { Pearson }\end{array}$ & p-value & Kesimpulan \\
\hline pertanyaan_1 & $-0,115$ & 0,019 & Valid \\
pertanyaan_2 & 0,176 & 0,008 & Valid \\
pertanyaan_3 & 0,225 & 0,009 & Valid \\
pertanyaan_4 & $-0,187$ & 0,042 & Valid \\
pertanyaan_5 & 0,378 & 0,001 & Valid \\
pertanyaan_6 & 0,393 & 0,001 & Valid \\
pertanyaan_7 & 0,232 & 0,038 & Valid \\
pertanyaan_8 & 0,375 & 0,002 & Valid \\
pertanyaan_9 & 0,526 & 0,000 & Valid \\
pertanyaan_10 & 0,223 & 0,043 & Valid \\
pertanyaan_11 & 0,540 & 0,000 & Valid \\
pertanyaan_12 & 0,441 & 0,000 & Valid \\
pertanyaan_13 & 0,504 & 0,000 & Valid \\
pertanyaan_14 & 0,486 & 0,000 & Valid \\
pertanyaan_15 & $-0,173$ & 0,003 & Valid \\
pertanyaan_16 & $-0,082$ & 0,000 & Valid \\
pertanyaan_17 & 0,189 & 0,000 & Valid \\
pertanyaan_18 & 0,292 & 0,012 & Valid \\
pertanyaan_19 & 0,341 & 0,004 & Valid \\
pertanyaan_20 & 0,292 & 0,012 & Valid \\
\hline
\end{tabular}

Berdasarkan Tabel 3, nilai p_value < alpha (0.05) dianggap valid dan apabila lebih dari alpha dinyatakan tidak valid. Untuk masing-masing variabel terhadap total skor masing-masing dimensi memiliki nilai yang beragam dan didapat semua variabel adalah valid. Setelah itu dilakukan uji reliabilitasJawaban-jawaban responden harus konsisten sehingga dapat dikatakan reliable.

Tabel 4. Uji Reliabilitas

\begin{tabular}{ccc}
\hline $\begin{array}{c}\text { Dimensi } \\
\left(\mathrm{D}_{\mathrm{i}}\right)\end{array}$ & $\begin{array}{c}\text { Nilai Alpha } \\
\text { Cronbach }\end{array}$ & Kesimpulan \\
\hline $\mathrm{D}_{1}$ & 0,688 & Reliabel \\
\hline
\end{tabular}

Berdasarkan tabel di atas, nilai Alpha Cronbach untuk dimensi bernilai lebih dari 0,6, sehingga dapat dikatakan bahwa jawabanjawaban responden untuk tiap-tiap pertanyaan konsisten atau reliabel. Langkah selanjutnya adalah melakukan pemodelan Regresi dimana 
rata-rata nilai raport adalah $(\mathrm{Y})$ dan $\mathrm{X}_{1}$ adalah penggunaan dana BOS untuk pengembangan perpustakaan, $\mathrm{X}_{2}$ Penggunaan dana BOS untuk pembelajaran dan ekstrakurikuler siswa, $\mathrm{X}_{3}$ Penggunaan dana BOS untuk langganan daya dan jasa, $\mathrm{X}_{4}$ Penggunaan dana BOS untuk membantu siswa miskin, dan $\mathrm{X}_{5}$ adalah Pengunaan dana BOS untuk kegiatan dalam rangka penerimaan siswa baru. Sehingga didapatkan model regresi sebagai berikut :

Tabel 5. Uji Asumsi

\begin{tabular}{|c|c|c|}
\hline Uji Asumsi & Kriteria Pengujian & Kesimpulan \\
\hline Normalitas & $\begin{array}{l}\text { Hipotesis : } \\
\text { H0: Residual tidak berdistribusi normal } \\
\text { H1: Residual berdistribusi normal } \\
\text { Nilai Statistika Uji : } \\
\text { Nilai KS-Test }=0,926 \text {; Asymp.sig }=0.358 \\
\text { Keputusan :H0 ditolak jika nilai signifikan }<\alpha\end{array}$ & $\begin{array}{l}\text { H0 ditolak karena nilai sig }(0,358)>0,05 \\
\text { sehingga uji asumsi normalitas terpenuhi }\end{array}$ \\
\hline Linieritas & $\begin{array}{l}\text { Asumsi Linieritas terpenuhi apabila data } \\
\text { memencar disekitar angka } 0(\mathrm{nol}) \text { pada sumbu Y } \\
\text { serta tidak membentuk pola atau kecenderungan } \\
\text { tertentu }\end{array}$ & $\begin{array}{l}\text { Berdasarkan Gambar.1 Asumsi Linieritas } \\
\text { terpenuhi }\end{array}$ \\
\hline $\begin{array}{l}\text { Homoskedast } \\
\text { istias }\end{array}$ & $\begin{array}{l}\text { Asumsi Homoskedastistias terpenuhi jika data } \\
\text { menyebar secara acak }\end{array}$ & $\begin{array}{l}\text { Tidak terjadi heteroskedastisitas sehingga } \\
\text { data bersifat homogen }\end{array}$ \\
\hline Autokorelasi & $\begin{array}{l}\text { Nilai } \mathrm{dW}=1,666 \text { dengan } \mathrm{N}=60 \text { dan } \mathrm{K}=5 \\
\text { Sehingga nilai dL }(1,248) \text { dan } \mathrm{dU}(1,598) \\
\mathrm{du}<\mathrm{d}<4 \text {-dl } \\
1,598<1,666<2,752\end{array}$ & Tidak terjadi autokorelasi \\
\hline $\begin{array}{l}\text { Multikolinier } \\
\text { itas }\end{array}$ & $\begin{array}{l}\text { Asumsi terpenuhi apabila nilai } \mathrm{VIF}<5 \\
\text { VIF } X_{1}=1,046 \\
\text { VIF } X_{2}=1,653 \\
\text { VIF } X_{3}=1,403 \\
\text { VIF } X_{4}=1,218 \\
\text { VIF } X_{5}=1,180\end{array}$ & $\begin{array}{l}\text { Kelima variabel tersebut menghasilkan nilai } \\
\text { VIF }<5 \text { dengan demikian tidak terjadi } \\
\text { multikolinieritas dalam model regresi ini }\end{array}$ \\
\hline
\end{tabular}

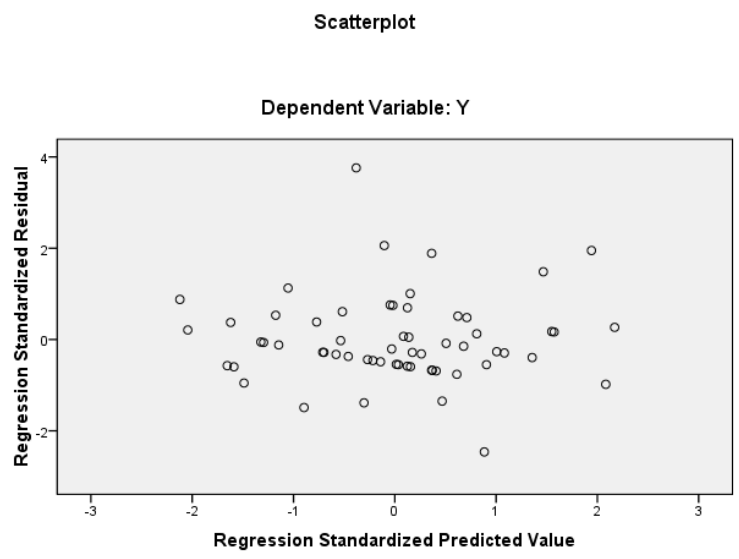

Gambar 2. Uji Linieritas

Berdasarkan analisis dengan Tabel.3 dapat disimpulkan bahwa semua asumsi terpenuhi langkah selanjutnya adalah menguji signifikansi koefisien (uji-t) dan uji kecocokan model (uji-F) dapat dilihat pada Tabel.6.
Tabel 6. Uji Siginfikansi dan Kecocokan Model

\begin{tabular}{|c|c|c|c|}
\hline Uji & & Keputusan & Kesimpulan \\
\hline $\begin{array}{l}\text { Uji- } \\
t\end{array}$ & $\begin{array}{l}\text { Hipotesis: } \\
\text { H0 : Koefisien } \\
\text { regresi tidak } \\
\text { signifikan } \\
\text { H1: Koefisien } \\
\text { regresi } \\
\text { signifikan } \\
\text { Taraf } \\
\text { Signifikansi: } \\
\alpha=5 \% \\
\text { Statistik Uji: } \\
\text { sig X1 }=0,000 \\
\text { sig X2 }=0,000 \\
\text { sig X3 }=0,000 \\
\text { sig X4 }=0,000 \\
\text { sig X5 }=0,000\end{array}$ & $\begin{array}{l}\text { H0 ditolak jika } \\
\text { nilai signifikan < } \\
\alpha . \text { Berdasarkan } \\
\text { nilai signifikansi } \\
\text { kelima variable } \\
\text { tersebut memiliki } \\
\text { nilai sig } \\
=0,000<0,005 \\
\text { sehingga H0 } \\
\text { diterima }\end{array}$ & $\begin{array}{lr}\text { Kelima } & \text { variabel } \\
\text { tersebut } & \text { signifikan } \\
\text { sehingga } & \text { dapat } \\
\text { digunakan } & \text { dalam } \\
\text { pemodelan } & \end{array}$ \\
\hline $\begin{array}{l}\text { Uji- } \\
\text { F }\end{array}$ & $\begin{array}{l}\text { Hipotesis: } \\
\text { H0: Model } \\
\text { yang } \\
\text { digunakan } \\
\text { tidak cocok } \\
\text { H1: Model } \\
\text { yang } \\
\text { digunakan } \\
\text { cocok } \\
\text { Statistik uji: }\end{array}$ & $\begin{array}{l}\text { H0 ditolak jika } \\
\text { nilai signifikan < } \\
\alpha . \text { Nilai sig }=0.000 \\
<0,005 \text { sehingga } \\
\text { H0 ditolak }\end{array}$ & $\begin{array}{l}\text { Moel yang } \\
\text { digunakan cocok }\end{array}$ \\
\hline
\end{tabular}




\section{Nilai sig=}

0.000

Berdasarkan uji tersebut didapatkan nilai $\mathrm{R}^{2}$ sebesar 77,33\% dan model Regresi untuk melihat hubungan antara rata-rata nilai raport (Y) terhadap $\mathrm{X}_{1}$ adalah penggunaan dana BOS untuk pengembangan perpustakaan, $X_{2}$ Penggunaan dana BOS untuk pembelajaran dan ekstrakurikuler siswa, $\mathrm{X}_{3}$ Penggunaan dana BOS untuk jasa, $\mathrm{X}_{4}$ Penggunaan dana BOS untuk membantu siswa miskin, dan $\mathrm{X}_{5}$ adalah Pengunaan dana BOS untuk kegiatan dalam rangka penerimaan siswa baru.

$$
\begin{gathered}
Y=\beta_{0}+\beta_{1} X_{1}+\beta_{2} X_{2}+\beta_{3} X_{3}+\beta_{4} X_{4}+\beta_{5} X_{5} \\
Y=75.0+0.514 X_{1}+0.038 X_{2}-0.006 X_{3+} \\
0.220 X_{4}-0.163 X_{5}
\end{gathered}
$$

\section{KESIMPULAN}

Berdasarkan analisis dapat disimpulkan bahwa rata-rata nilai rapot siswa dan siswi memiliki hubungan yang positif apabila dana BOS digunakan untuk penggunaan perpustakaan, pembelajaran dan ekstrakurikuler siswa, dan siswa miskin. Sedangkan hubungan jasa dan penerimaan siswa baru memiliki hubungan yang negative. Selain itu didapat nilai $\mathrm{R}^{2}$ sebesar $77,33 \%$ hal ini dapat diinterpretasikan bahwa rata-rata nilai rapot siswa $(\mathrm{Y})$ dapat dijelaskan oleh variabel $\mathrm{X}_{1}, \mathrm{X}_{2}, \mathrm{X}_{3}, \mathrm{X}_{4}$, dan $\mathrm{X}_{5}$ sedangkan $22,67 \%$ lain dipengaruhi oleh faktor lain diluar penelitian ini

\section{DAFTAR PUSTAKA}

Gujarati, D. (2007). Dasar-dasar Ekonometrika. Alih Bahasa: Julius A. Mulyadi. Jakarta : Erlangga.

Kementerian Pendidikan dan Kebudayaan. (2009) Pedoman Operasional BOS provinsiJawa Barat. Bandung: Dinas Pendidikan Provinsi Jawa Barat, Sardiman. (1995). Interaksi dan Motivasi Belajar Mengajar. Jakarta: Rajawali Press,

Saroni, Mohammad. (2010). Orang Miskin Harus Sekolah. Jogjakarta: Ar-Ruzz Media,

Slameto. (1998). Belajar dan faktor-faktor yang mempengaruhinya. Jakarta: Bina Aksara,Cet. I,

Sudjana, Nana. (1995). Dasar-Dasar Proses Belajar Mengajar. Bandung: Sinar Baru AlGensindo,

Supranto, J. (2004). Ekonometri Buku Kedua. Jakarta : Ghalia Indonesia.

Supranto, J. (2005). Ekonometri Buku Kesatu. Jakarta : Ghalia Indonesia.

Syah, Muhibbin. (2000). Psikologi Pendidikan dengan Pendekatan Baru. Bandung: Remaja Rosdakarya,

Undang-undang RI No. 20 Tahun 2003, Sistem Pendidikan Nasional. Jakarta: Sinar Grafika. 